\title{
Registro Docente Contemporâneo: infấncia e docência em tempos digitais
}

\author{
Cláudia Inês Horn' \\ Elí Henn Fabris"
}

'Centro Universitário Univates (UNIVATES), Lajeado/RS - Brasil "Universidade do Vale do Rio dos Sinos (UNISINOS), São Leopoldo/RS-Brasil

\begin{abstract}
RESUMO - Registro Docente Contemporâneo: infância e docência em tempos digitais. O artigo objetiva articular a infância contemporânea com a prática de registro docente da documentação pedagógica. Abordando-se a educação da infância contemporânea e mostrando-se os deslocamentos nos modos de viver dos sujeitos infantis, tensiona-se o modo de ser aluno e docente na Educação Infantil. Analisam-se referenciais italianos que apresentam a abordagem da documentação pedagógica, e defende-se a ideia de que essa forma de registro aponta para um gradual refinamento nas maneiras de registrar as ações infantis, sugerindo um tempo digital e pontilhista, permeado pela rapidez nos modos de comunicar as aprendizagens. Uma criança protagonista e um professor organizador dos tempos e espaços são visibilizados na literatura italiana analisada.

Palavras-chave: Infância. Educação Infantil. Documentação Pedagógica. Tempo Digital.
\end{abstract}

ABSTRACT - Contemporary Teacher's Records: childhood and teaching in digital times. This paper aims to articulate the contemporary childhood with the practice of teaching record of pedagogical documentation. When approaching the contemporary children education and pointing out displacements in the child subjects' ways of living, the paper problematizes the ways of being a student and a teacher in Child Education. We have also analyzed some Italian references addressing the pedagogical documentation approach, and we advocate the idea that this type of record evidences a gradual refinement in the ways of recording children's actions, thus suggesting a digital, pointillist time permeated with fast ways of conveying information. A protagonist child and a teacher who organizes times and spaces have been evidenced in the Italian literature under analysis. Keywords: Childhood. Child Education. Pedagogical Documentation. Digital Time.

Educação \& Realidade, Porto Alegre, v. 42, n. 3, p. 1103-1122, jul./set. 2017. 1103 http://dx.doi.org/10.1590/2175-623660624 
A 'estratégia' requer a capacidade de aproveitar e trabalhar com as oportunidades e as conexões que emergem do contexto educativo; a estratégia é feita ao mesmo tempo em que a ação acontece, e é a arte de usar a informação produzida na ação e de incorporá-la, a fim de desenvolver planos de ação no momento - o 'aqui e o agora' -, possibilitando ao intérprete tirar o máximo de certeza daquilo que é incerto (Fortunati, 2014, p. 22)

O presente artigo tem como objetivo articular duas discussões. A primeira aborda a infância contemporânea, e a segunda refere-se ao registro docente da aprendizagem das crianças no contexto escolar, problematizando o tempo de ser aluno na Educação Infantil. Este escrito parte de uma pesquisa de doutorado em Educação iniciada em março de 2013 em desenvolvimento no Programa de Pós-graduação em Educação da Universidade do Vale do Rio dos Sinos/Unisinos. Esta investigação tem como objetivo analisar como a infância vem sendo visibilizada no registro docente sobre as aprendizagens das crianças da Educação Infantil, especialmente nos registros denominados documentação pedagógica. Tomamos como documentação pedagógica a abordagem de registro colocada em ação a partir de uma determinada literatura pedagógica, a qual resolvemos chamar de referenciais italianos.

No nosso ponto de vista, a documentação pedagógica enquanto prática de registro docente sobre as aprendizagens das crianças, aponta para um gradual refinamento nas maneiras de registrar as ações infantis na escola, sugerindo um tempo pontilhista e efêmero, permeado por rapidez nos modos de comunicar as aprendizagens, tal como pretendemos mostrar ao longo deste escrito. Processo que não é isento de sentidos, pelo contrário, esses deslocamentos incidem tanto sobre a criança, quanto sobre o docente, produzindo sujeitos e práticas alinhadas ao contemporâneo. Assim, o foco central deste artigo está na articulação entre os modos de viver a infância contemporânea e os modos de fazer registro docente na Educação Infantil. Na primeira seção, apresentamos uma breve contextualização da Educação Infantil no cenário nacional e procuramos mostrar os deslocamentos nos modos de viver dos sujeitos infantis, apontando para a institucionalização e escolarização da infância. Na segunda seção, apresentamos alguns fundamentos da abordagem da documentação pedagógica como forma de registrar as aprendizagens das crianças, tomando como corpus analítico um conjunto de obras que denominamos de referenciais italianos, tais como: Edwards, Gandini e Forman (1999; 2016); Rabitti (1999); Gandini e Goldhaber (2002); Gandini e Edwards (2002); Dahlberg, Moss e Pence (2003); Azevedo e Oliveira-Formosinho (2008); Kinney e Wharton (2009); Fortunati (2009; 2014); Luff (2010); Gandini, Hill, Cadwell e Schwall (2012); Rinaldi (2012); Ceppi e Zini (2013).

Na terceira seção, sugerimos possíveis relações entre a infância contemporânea e os modos de registro docente, ambos articulados num tempo pontilhista e fugaz, um tempo que muitos autores têm chamado de líquido (Bauman, 2001), pós-moderno (Lyotard, 1998), hiper- 
modernidade (Lipovetsky, 1989), modernidade tardia (Giddens, 1991), modernidade reflexiva (Beck, 1997) ou segunda modernidade (Sarmento, 2004), entre outras expressões que nos interessam para pensar as transformações que constituem os modos de subjetivação dos sujeitos infantis. Por fim, buscamos mostrar que esses registros operam como tecnologias, fabricando modos muito particulares de ser criança-aluno-infantil na Contemporaneidade.

Inspiradas na epígrafe acima, pretendemos tensionar práticas pedagógicas centradas no "aqui e agora" que visam a criar estratégias educacionais "ao mesmo tempo em que a ação acontece" e aproveitam as ferramentas tecnológicas para registrar um tempo "produzido na ação”. Vimos emergir na Educação Infantil um tempo escolar digital, carregado com outros ritmos para a infância contemporânea e com outras configurações para o trabalho docente.

\section{AEducação da Infância: em busca de mais Educação Infantil}

É visível a busca por “mais” Educação Infantil no cenário brasileiro ${ }^{1}$ Em primeiro lugar, citamos os avanços nas últimas décadas na legislação brasileira: a Constituição Federal (Brasil, 1988), o Estatuto da Criança e do Adolescente (Brasil, 1990), a Lei de Diretrizes e Bases da Educação Nacional (Brasil, 1996) e as Diretrizes Curriculares Nacionais para a Educação Infantil (Brasil, 1998/2009), entre outras. A criança passa a ser concebida como sujeito de direitos, convocando-se a família e o estado brasileiro a atuar no atendimento de qualidade (optamos por não citar aqui, mesmo reconhecendo sua importância, os demais documentos do Ministério da Educação publicados com a intenção de garantir qualidade no atendimento da Educação Infantil). Em segundo lugar, acompanhamos algumas políticas públicas: investimentos na formação continuada dos docentes, especialmente para aqueles profissionais em serviço que ainda não haviam cursado a graduação, tal como aponta o Plano Nacional de Formação de Professores da Educação Básica (Parfor); investimentos na formação inicial, como o Programa Institucional de Bolsa de Iniciação à Docência (Pibid); os debates acerca da Base Nacional Comum, incluindo Eixos para a Educação Infantil; a ampliação das vagas para as crianças de 0 a 5 anos por meio do Programa Nacional de Reestruturação e Aquisição de Equipamentos para a Rede Escolar Pública de Educação Infantil (Proinfância), que visa à construção de novas escolas e à qualificação de escolas existentes.

Também em relação ao Plano Nacional de Educação (Brasil, 2014), a meta número 1 define a ampliação da oferta de vagas em creches, atendendo, no mínimo, 50\% das crianças de até 3 anos de idade até o final da vigência do PNE, além de, até 2016, atender à matrícula de todas as crianças de 4 e 5 anos de idade na pré-escola. Como pudemos acompanhar, paulatinamente, a Educação Infantil, enquanto primeira etapa da Educação Básica, vem ganhando fôlego nos debates políticos e institucionais, representando um direito da criança e um dever do Estado, como aponta a legislação brasileira. Mais escolas, mais vagas, mais 
tempo integral na escola, mais profissionais, mais profissionalismo na Educação Infantil.

Este cenário atual está atrelado aos deslocamentos históricos das práticas de atendimento às crianças no Brasil, bem como às intervenções do Estado na infância, construindo uma caminhada muito particular para essas instituições de atendimento. É importante compreender como, nos diferentes momentos históricos, a Educação Infantil e a concepção de infância estão permeadas por um regime de verdade específico de determinada época. A sua trajetória histórica no Brasil carrega traços de assistencialismo e custódia, com caráter médico-higienista e sanitarista (Kuhlmann Júnior, 1998; 2003; Kramer, 2001; Bujes, 2002; Oliveira, 2002).

O pensamento moderno faz emergir novas formas de conceber a infância e a criança, ou seja, as sociedades modernas construíram a necessidade de criação e consolidação de instituições específicas para educar a infância e proteger a criança, separando-a do mundo adulto. Assim, a instituição escolar e os saberes científicos da pedagogia, por exemplo, tomam para si o direito e o dever de dizer e escrever sobre o sujeito infantil e suas formas de vida, emitindo orientações sobre comportamento, aprendizagem, amizade, postura, boas maneiras, entre outros. A conformação do pensamento moderno desencadeia a institucionalização e escolarização da infância.

Tal institucionalização e escolarização da infância pode ser visibilizada através da emergência das práticas de assistência à infância no Brasil e a proliferação das políticas na atualidade que, inicialmente apresentavam caráter de filantropia caritativa e geralmente estavam ligadas a ordens religiosas ligadas, especialmente através de igrejas e conventos (Lockmann; Mota, 2013). Nesse contexto, a roda dos expostos, inventada na Europa Medieval, foi considerada uma das primeiras formas de atendimento à infância no Brasil, sobretudo a infância pobre. Essa primeira instituição de assistência caritativa à infância cumpriu importante papel no Brasil (Marcílio, 2003, p. 53), uma vez que, mesmo minoritária no "conjunto da infância abandonada do país nos séculos XVIII, XIX e mesmo no XX, foi no entanto a melhor documentada, mesmo considerando-se todos os demais segmentos da população infantil" (Marcílio, 2003, p. 73) ${ }^{2}$.

Posteriormente, acompanhamos o ingresso dos médicos higienistas que, preocupados com a alta mortalidade dentro dessas instituições, propuseram novas leis de atendimento à infância abandonada (Marcílio, 2003, p. 68). Gradativamente, a caridade deu lugar à filantropia, fundamentada na ciência e interessada na educação, instrução e moralização das crianças. Com "a fase do Estado do Bem-Estar”, a partir de 1960, surgem outros modelos de atendimento à infância abandonada, em que "o Estado assume enfim a sua responsabilidade sobre a assistência à infância e à adolescência desvalidas, e estas tornam-se sujeitos de Direito" (Marcílio, 2003, p. 79).) Entre as últimas décadas do século XIX e o início do século XX, há a passagem "de uma filantropia caritativa, na qual a preocupação com a salvação das almas era priori-

1106 Educação \& Realidade, Porto Alegre, v. 42, n. 3, p. 1103-1122, jul./set. 2017. 
tária, para uma filantropia higiênica, para a qual a preocupação central se direciona à vida biológica e aos efeitos que ela pode causar à sociedade" (Lockmann; Mota, 2013, p. 99). Novas táticas de governo foram necessárias: um controle político-biológico da população, mediante o discurso médico-higienista, capaz de prevenir ameaças, doenças e a morte a partir de um controle minucioso no sujeito, seus hábitos, suas formas de vida.

A população infantil, entendida como um problema ou ameaça social, necessita ser educada e a sociedade começa a reclamar por mais instituições para a infância, ou seja, por mais escolas, e a necessidade de escolarização das crianças, tanto pobres, quanto ricas, passa a ser crescente no Brasil. Vemos surgir a escola de massa por volta de meados do século XIX e um discurso higienista e sanitarista nos currículos para as crianças pequenas, produzindo a criança como aluno. Cada modelo pedagógico produz um sujeito pedagógico diferenciado, um aluno contingente ao seu tempo e espaço; portanto, podemos dizer que ele é produzido no interior de discursos e de práticas de governo. No caso dos sujeitos infantis, conforme Narodowski (1998), são os discursos da psicologia educacional e da pedagogia que possuem uma grande força na produção do que hoje temos como aluno.

Com o processo de escolarização, compreendemos a criança enquanto aluno, e sua vida começa a ser estruturada em rituais e fases de desenvolvimento. Popkewitz (1994) afirma que a categoria de aluno passou a existir fortemente no século XIX e que sua invenção reconstruiu a criança como objeto de manipulação. O autor ressalta que a moderna criança escolar é aquela que “aprende a ser um 'cidadão', que tem responsabilidades abstratas relacionadas ao governo do Estado, que tem 'potencial' como trabalhador, que aprende habilidades e sensibilidades culturais para 'uso' futuro e que é automonitorada em seu desenvolvimento afetivo e cognitivo” (Popkewitz, 1994, p. 179).

A criança, vista como aluno e aprendiz, convive nos ambientes escolares com o processo de avaliação e com registros sobre sua aprendizagem. Como destacamos acima, os discursos médico-higienistas tiveram implicações nas formas de registro dos alunos, trazendo a necessidade de detalhar em cadernetas, boletins semestrais ou anuais e relatórios a "interioridade dos escolares" (Ó, 2009, p. 48). Não bastava medir o saber; era preciso conhecer o ser em sua minúcia, ampliando e ramificando os registros sobre a criança, de modo que ela pudesse ser "capturada e apresentada de forma estável, fixa” (Ó, 2009, p. 51). A observação, a mensuração, a quantificação, como todo aparato de imagens, gráficos, quadros, diagramas e números vistos em boletins, dossiês, fichas, estudos de casos, cadernetas, testes de inteligência e questionários (fazer-falar e narrar a si próprio, como a confissão), serviam para acompanhar o desenvolvimento físico e mental da criança, num registro detalhado e exclusivo. "Era, portanto, essencial que se desenvolvessem, aperfeiçoassem e estabilizassem sistemas de descrição visual das características, em si mesmas visíveis, tanto do corpo como da mente infantil" (Ó, 2009, p. 52-53). 
Acreditamos que, para a concretização do projeto de mais Educação Infantil no cenário brasileiro, foi necessário um incansável movimento de reconhecimento dessa primeira etapa para os processos de escolarização. Destacamos que um desses movimentos (e aquele que nos interessa pensar neste artigo) foi levar a avaliação para esse nível de ensino. Entretanto, como desde a sua emergência a Educação Infantil não conta com retenção nem reprovação de crianças, foi necessário construir um refinado modelo de observação e registro. Inúmeras pesquisas e publicações são destinadas a esse assunto, e, ainda que existam diferenças entre ideias e fundamentos, parece-nos que todas estão unidas na defesa da necessidade de os professores observarem cada criança para registrar e avaliar a aprendizagem, a fim de propor melhorias, avanços, maior desempenho e eficácia nos modos de aprender.

Atualmente, acompanhamos a celebração da criança como sujeito de direitos, ativa, rica em criatividade, protagonista de sua vida, com potencial para fazer as suas próprias escolhas. Exaltamos na escola contemporânea o princípio da liberdade (preceito que emerge na Modernidade), em que as crianças, desde tenra idade, têm autonomia para decidir sobre as temáticas e os projetos que querem seguir adiante, quando desejam aprender sobre outros assuntos e em quais os espaços escolares preferem estar. Entram em cena, cada vez de forma mais potente, as pedagogias para a pequena infância, em que a ênfase está na centralidade da criança no processo de aprendizagem, destacando um sujeito infantil autorregulado, capaz de fazer suas próprias escolhas a partir dos seus interesses e vontades. Nesse aspecto, corroboramos o que mostram alguns autores sobre os deslocamentos de uma sociedade centrada no ensino para uma sociedade centrada na aprendizagem (Popkewitz; Olsson; Petersson, 2009; Noguera-Ramírez, 2011; Biesta, 2013; Fabris; Traversini, 2013).

A Contemporaneidade aponta para a pluralização dos modos de ser criança e para a necessidade de heterogeneização da infância enquanto categoria social geracional, propondo o termo infância no plural, a fim de indicar a multiplicidade das formas de vida infantil (Sarmento, 2004). Já outros autores, como Postman (1999) e Buckingham (2007), preferem utilizar a expressão "morte da infância” para sinalizar o desaparecimento da concepção de infância construída na Modernidade e sinalizar a emergência de uma infância pós-moderna. Não pretendemos, entrar na seara de definições; antes, queremos visibilizar as transformações nos modos de viver a infância - o que tem produzido tipos muito específicos de sujeitos infantis na Educação Infantil e provocado mudanças nas formas de ser criança, de viver a vida infantil, bem como nas formas de os adultos se relacionarem com ela e nas práticas escolares. Conforme destaca Marín-Díaz (2010), antes de pensar na morte da infância moderna ou no surgimento de outra figura infantil, “[...] parece-me que as condições e práticas contemporâneas possibilitaram a consolidação da concepção de infância liberal fundamentada na ideia de autonomia, liberdade, interesse, desejo e direitos" (Marín-Díaz, 2010, p. 206).

1108 Educação \& Realidade, Porto Alegre, v. 42, n. 3, p. 1103-1122, jul./set. 2017. 
Ao contextualizar a Educação Infantil no cenário nacional percebemos o quanto caminhamos para a institucionalização e a escolarização da infância. As transformações na sociedade em suas diferentes ênfases, em diferentes momentos e espaços acabam produzindo tanto as novas subjetividades infantis, quanto as subjetividades docentes. Neste sentido, a instituição escolar, por vezes vista como mais flexível e emancipatória, formando sujeitos livres e autônomos, exerce seu poder no sujeito e na população infantil de forma mais sutil e refinada, escolarizando seus modos de vida. Vinculamos a esse cenário a necessidade da avaliação constante, ou a "exacerbação da avaliação" (Veiga-Neto, 2013), visto que, ao se garantirem a flexibilidade e a liberdade, é preciso fazer movimentar certo modo de avaliar as crianças bastante particular, o qual também prima pela flexibilidade e liberdade. Dito de outro modo, é necessário fazer proliferar estratégias de avaliação para uma criança-aluno-infantil que é livre na escola, que é capaz de fazer suas próprias escolhas, a fim de garantir e dar visibilidade para a aprendizagem infantil. Talvez isso justifique a celebração e festejo da documentação pedagógica como uma forma de registro muito potente entre a comunidade docente, e também de seus ajustes à sociedade neoliberal, em que vivemos outros tempos, não mais somente analógicos, mas intensamente digitais. Acreditamos que esse tempo digital, quando envolve a modulação das vidas dos sujeitos infantis, tem produzido singulares subjetividades que se ajustam ao mundo contemporâneo.

Com isso, outras formas de registro docente vão emergir na escola: mais instantâneas, transparentes, que não apenas mostrem números e dados escritos, mas utilizem imagens e narrativas em movimento. Será necessária a construção de outras formas de avaliação, não centradas no diagnóstico e na elaboração de pareceres e relatórios de avaliação trimestrais ou semestrais; será preciso apresentar outra estética na produção do material, utilizando-se diversos recursos, como fotos e filmagens, num tempo que prima pela rapidez, permanência e aceleração do registro. A seguir, procuramos mostrar essas evidências e recorrências nos referenciais italianos analisados neste trabalho. Entretanto, queremos deixar claro que não nos posicionamos contra a documentação pedagógica, pois entendemos que essa posição não nos deixaria vasculhar as "entranhas" dos processos; queremos, sim, seguir os passos de sua constituição como uma verdade naturalizada nas práticas pedagógicas brasileiras, mais especificamente, no sul do Brasil. É o que tentaremos mostrar com a análise aqui produzida. Outro alerta é importante: ao nos centrarmos em uma análise dos referenciais italianos, temos consciência do espaço que acontece entre o que é proposto nos referenciais e as práticas docentes exercidas nas escolas de Educação Infantil, a multiplicidade de sentidos é intensa, por isso a importância do exercício do pensamento acompanhar cada ação pedagógica. Eis o nosso compromisso. 


\section{A Documentação Pedagógica como Registro das Aprendizagens: o que estamos produzindo?}

Como deixamos claro anteriormente, a expressão documentação pedagógica emerge a partir de um conjunto de obras que, neste trabalho resolvemos denominar de referenciais italianos. Sabemos que nem todos os autores dessas obras são de origem italiana, entretanto, no nosso ponto de vista, o que os une é o interesse em conhecer e estudar mais sobre a proposta de educação infantil oferecida em diferentes cidades da Itália. Essas obras abordam a possibilidade de fazer a documentação pedagógica como estratégia para tornar visível o processo de aprendizagem das crianças na escola, refinando as formas de registro docen$\mathrm{te}^{3}$. Embora seja possível reconhecer a presença dos registros sobre a criança muito antes desses referenciais italianos, conforme proposta de pensadores de diversos países (Montessori, 1965; Freinet, 1969; 1976; Warschauer, 1993; Freire, 1996), é visível que esses referenciais italianos têm impacto nas escolas e fazem movimentar outras possibilidades de registro, incluindo filmagens, fotografias, transcrição de falas das crianças, entre outros recursos, primando pela rapidez na sua forma de comunicação e possibilidade de registro de instantâneos da rotina escolar.

Lóris Malaguzzi pode ser considerado um pensador inicial e fundamental nas escolas de Reggio Emilia ${ }^{4}$ - um "[...] arquiteto do pensamento pedagógico e filosófico que permeia a experiência de Reggio" (Rinaldi, 2012, p. 138). Ele traz influências no debate sobre a documentação pedagógica, destacando a exigência de educadores infantis, os quais “[...] devem descobrir modos de comunicar e documentar as experiências crescentes das crianças na escola, devendo preparar o fluxo constante de informação de qualidade, voltado aos pais, mas também apreciado pelas crianças e pelos professores" (Malaguzzi, 1999, p. 80). $\mathrm{O}$ autor defende a ideia de que os adultos aprendem sobre as crianças quando convivem com elas. Assim, procura construir outra imagem de criança, não padronizada, não universal, não definida por manuais, mediante a "pedagogia da escuta” (Rinaldi, 2012, p. 124).

A abordagem italiana apresenta uma criança protagonista e capaz, colocando-a no centro dos processos educacionais, pois é "sujeito ativo, competente e construtivo" (Fortunati, 2014, p. 18), cidadão pleno em seus direitos. Destaca-se uma imagem forte e rica da criança, ou seja, um “[...] sujeito rico significa uma criança que é competente e curiosa, sociável e forte, e ativamente engajada na criação de experiências e na construção de sua própria identidade e de seu próprio conhecimento" (Fortunati, 2014, p. 20). O sujeito infantil tem um “[...] organismo dotado de um dinamismo interativo imediato, portanto, capaz de estabelecer relações com uma variedade de pessoas e contextos que fazem parte da sua experiência” (Fortunati, 2014, p. 91).

Diante desta imagem forte da criança é que Malaguzzi (1999) desencadeia a prática - ou o instrumento metodológico - da documentação pedagógica. Entendida como um processo cooperativo que auxilia

1110 Educação \& Realidade, Porto Alegre, v. 42, n. 3, p. 1103-1122, jul./set. 2017. 
professores a observar, escutar e, assim, entender melhor as crianças, a documentação pedagógica é compreendida como "um 'anticorpo' extremamente poderoso contra a proliferação de ferramentas de aferição e avaliação cada vez mais anônimas, descontextualizadas e só aparentemente objetivas e democráticas" (Rinaldi, 2012, p. 119-120). Na abordagem de Reggio Emilia, por exemplo, a documentação não é vista como um trabalho isolado e o professor não se preocupa com os passos finais, com os resultados (Kinney; Wharton, 2009). Entretanto, é fundamental documentar o processo de interação e criação, e tudo isso é analisado no coletivo de professores, ou seja, a documentação é um importante instrumento de trabalho docente. A análise e a interpretação da documentação auxiliam os professores a esboçar roteiros de ação, uma vez que não se trata de coleta de dados para serem arquivados. Assim, a documentação pode contribuir como uma estratégia para, além de buscar o envolvimento com as famílias, preservar as memórias no tempo e no espaço, dando visibilidade às experiências vivenciadas pelas crianças e possibilitando ao professor e às próprias crianças revisitar, reconstruir, ressignificar esses momentos vivenciados no contexto escolar (Kinney; Wharton, 2009).

Ao mostrar a centralidade na criança, a abordagem italiana apresenta um estatuto bastante particular para o professor, uma vez que este deve refletir sobre o processo educacional, sabendo narrar e descrever as crianças e mostrando o seu trabalho. Por esse motivo, cabe ao professor desenvolver uma escuta atenta àquilo que dizem as crianças, bem como às suas formas de aprender, conviver e brincar com os outros amigos na escola. Para Rinaldi (2012, p. 129), “[...] os educadores que sabem como observar, documentar e interpretar os processos que as crianças experimentam autonomamente perceberão, nesse contexto, seus maiores potenciais para aprender como ensinar". Trata-se de descentralizar as funções do professor em relação às crianças, visto que “[...] o educador deixa de ter um papel central na relação com a criança e, com os pais, passa a ser um educador que coloca todo o seu profissionalismo na ação sobre os contextos que acolhem as relações entre crianças e entre pais" (Fortunati, 2014, p. 59).

O professor, visto como "observador incansável e coprotagonista" (Fortunati, 2014, p. 71), deve ter competências para mediar ações, oferecer variados recursos na organização dos espaços escolares e interessar-se em "organizar as oportunidades de apoio às experiências das crianças" (Fortunati, 2014, p. 21). O papel do adulto na escola desloca-se para um sujeito coprotagonista, como podemos perceber no excerto abaixo:

[...] a atribuição e o reconhecimento às crianças de uma identidade rica em protagonismo requerem uma transformação no papel do adulto em uma direção na qual sua ação seja conduzida muito mais sobre a organização de contextos estruturantes do que sobre estímulos diretos na ação das crianças; muito mais na capacidade de reconhecimento e expansão da diversidade de estilos comportamentais das crianças do que a ansiedade de levá-las a um 
desempenho preciso e predefinido; muito mais na atenção aos processos da ação como expressão de uma estratégia evolutiva do que desejo de certificar-se sobre o estágio de desenvolvimento alcançado a partir de supostos parâmetros gerais: a dimensão que surge é a do diálogo, da partilha, das trocas e da comparação (Fortunati, 2014, p. 21).

Nesse sentido, podemos salientar que observação, interpretação e documentação são itens importantes na prática docente, pois mediante os registros o pensamento do professor "se torna material, isto é, tangível e capaz de ser interpretado" (Rinaldi, 2012, p. 131), ou seja, se torna objetivo. O professor ao fazer a documentação, não ensina uma série de regras nem apresenta fórmulas e métodos, mas sim tem "a cultura do pensamento baseado em projetos" (Rinaldi, 2012, p. 138). Portanto, a documentação pode ser compreendida como uma possibilidade de tornar visível a construção da memória do grupo de crianças em seu contexto escolar, trazendo os conceitos de observação, registro e reflexão como ações estruturantes e inerentes ao processo de documentar, estando conectada com a pedagogia de projetos.

Fazemos uma breve exposição sobre o conceito de projeto que vem sendo postulado nos referenciais italianos, o que possibilita sustentar a abordagem da documentação pedagógica: os projetos visam a ajudar a criança a extrair um sentido mais profundo e completo de eventos e fenômenos de seu próprio ambiente e de experiências que mereçam a atenção. Os projetos oferecem a parte do currículo na qual as crianças são encorajadas a tomar suas próprias decisões e a fazer suas próprias escolhas, geralmente em cooperação com seus colegas, sobre o trabalho a ser realizado. O trabalho em projetos faz com que as crianças contribuam com seus próprios conhecimentos, sugerindo questões a serem indagadas e linhas de investigação a seguir. Elas assumem liderança no planejamento e responsabilidades por observações específicas, por informações e pelos artefatos coletados e, além disso, seus interesses, ideias, preferências e escolhas podem ter rédeas relativamente soltas. Os professores prestam atenção, constantemente, às atividades das crianças e acreditam que, quando elas trabalham em um projeto de seu interesse, encontrarão naturalmente problemas e questões para investigar. O papel do professore é ajudá-las a descobrir seus próprios problemas e questões. Nesse ponto, não oferecerão soluções fáceis, mas, em vez disso, ajudarão as crianças a focalizar um problema ou dificuldade e a formular hipóteses (Edwards; Gandini; Forman, 1999).

Ao analisar as referidas obras italianas, também evidenciamos, conforme já destacamos acima, a entrada de novas ferramentas tecnológicas para o registro docente, articuladas, muitas vezes, ao trabalho nos ateliês (aspecto que merece destaque nas propostas italianas). Há uma valorização da rapidez na comunicação dos registros, sendo que os professores têm um tempo em serviço para documentar as aprendizagens das crianças quase instantaneamente. Apresentamos alguns excertos do material empírico que sugerem a importância do uso de tecnologias atreladas à rapidez na comunicação:

1112 Educação \& Realidade, Porto Alegre, v. 42, n. 3, p. 1103-1122, jul./set. 2017. 
Os professores usam a tecnologia diariamente para processar vários documentos, como as conversas das crianças, cartas aos pais, fotografias tiradas com câmeras digitais e documentação que será colocada na parede da sala de aula. $\mathrm{O}$ computador do ateliê funciona como um servidor $\mathrm{e}$ pode ser acessado de outros computadores nas salas de aula. Isso aumentou a eficiência do nosso trabalho, pois os professores têm tempo durante o dia para trabalhar na documentação e podem acessar todos os seus arquivos de qualquer computador. $\mathrm{O}$ ateliê é um espaço que pode ajudar na produção da documentação, assim como nos levar para novas formas, como vídeo, tipos variados de livros $e$ outros meios digitais (Schwall, 2012, p. 42, grifo nosso).

[...] começamos a documentar, a registrar sistematicamente, com uma série de recursos dos meios de comunicação, incluindo fotografias, vídeos e gravações em áudio, o que as crianças nos contavam (Kinney; Wharton, 2009, p. 22, grifo nosso).

[...] os educadores precisam ser observadores perspicazes, atentos para as possibilidades de aprendizagem e portadores de câmeras fotográficas, câmeras de vídeo e gravadores de áudio, sempre 'prontos' para captar estes momentos extraordinários (Kinney; Wharton, 2009, p. 29, grifo nosso).

Enfim, como pudemos observar, há uma inclinação bastante pontual emergindo dos referenciais italianos e das pesquisas que, por ora, parecem festejar os benefícios da documentação nas práticas escolares da Educação Infantil. Nossa intenção, nesta seção, não foi esgotar os princípios que fundamentam as diferentes abordagens italianas para a educação da infância; antes, pretendemos assinalar alguns fundamentos da documentação pedagógica, compreendida como uma nova forma de registrar as aprendizagens das crianças. Destacamos que as crianças ocupam a centralidade nos processos educacionais, sendo protagonistas de suas ações e os adultos ocupam, talvez, um lugar mais periférico, de coprotagonistas e gerenciadores das ações infantis, preocupando-se com a organização dos espaços e com o registro daquilo que as crianças escolheram fazer na rotina escolar. Esses registros devem primar pela instantaneidade e rapidez na comunicação, trazendo as ferramentas tecnológicas como aliadas para este tempo digital. Essa maneira de praticar a vida na escola infantil, tanto por parte das crianças, quanto por parte dos professores, desloca-se de um tempo analógico para um tempo digital e encaixa-se nas racionalidades neoliberais, assunto que procuramos debater a seguir.

\section{Do Tempo Analógico ao Tempo Digital. 0 que Precisamos Registrar?}

Pretendemos apresentar como as transformações na forma de registro docente - essa mudança de ênfase - estão articuladas com os deslocamentos na forma de pensar a infância contemporânea e aos modos atuais de as crianças viverem suas vidas. A expressão mudança de ênfa- 
se pretende assinalar a passagem de uma forma de registro voltada à escrita docente, numa lógica temporal, analógica, voltada ao trimestre ou semestre escolar e, portanto, aparentemente mais duradoura e sólida, para registros mais diários e momentâneos. Dito de outra forma, trata-se de registros com o objetivo de documentar muitas ações infantis no momento em que acontecem, incluindo, para além da escrita, fotografias, filmagens, transcrições de falas das crianças, entre outros recursos - um registro do tempo digital. Contudo, isso não significa a ausência da escrita, mas sua transformação. Parece-nos que nessa forma de registro se busca o congelamento da ação vivida na escola, a captura do que cada criança consegue realizar.

Desse modo, o registro da documentação pedagógica torna-se produtiva numa época em que o sujeito (professor e aluno) precisa ser livre, fazer suas próprias escolhas, aprender o tempo todo, extraindo o máximo de suas próprias potencialidades nas comunidades de aprendizagem. É justamente o investimento no sujeito autônomo, livre, responsável pela sua própria educação, que interessa para as racionalidades neoliberais, conectadas com as transformações contemporâneas. Ao enfatizar a centralidade na criança, reconfigura-se o papel do professor como um gerenciador de oportunidades, valorizando mais a organização do espaço da sala de aula e da escola. As iniciativas das crianças, seus interesses individuais, seu empreendedorismo particular é que conduzem as ações pedagógicas, e, como uma atitude mais inovadora, os docentes registram, fotografam, filmam, descrevem suas ações para mostrar à comunidade em geral, espetacularizar a vida escolar infantil e produzir certo marketing das aprendizagens infantis.

Cabe ressaltar aqui que muitas pedagogias já vêm buscando, por longos anos e cada uma a seu modo, desprender esforços para mostrar o quanto o sujeito aprendente precisa ser ativo no seu processo de aprendizagem, destacando a centralidade na criança e o interesse infantil como elementos fundamentais para o processo escolar. Ser ativo e ter interesses é condição para as aprendizagens infantis. Nesse sentido, podemos relembrar aqui as teorizações, especialmente de Rousseau, Herbart, Claparède, Dewey e Froebel, que, desde meados do século XVIII, e mais intensamente no século XIX e início do século XX, já postulavam a centralidade na criança e a noção de interesse infantil como questões centrais para organizar os processos educativos. Portanto, a centralidade na criança e a noção de interesse não são temas novos na Educação Infantil, entretanto, a partir da análise que desenvolvemos dos referenciais italianos, percebemos novas nuances dessa centralidade e do próprio interesse infantil, o que acaba produzindo outras roupagens para as crianças do nosso tempo, denominadas atualmente como protagonistas. Com isso, queremos afirmar a nossa hipótese de que as práticas de registro da documentação pedagógica (não apenas essas práticas, mas tantas outras postas em ação pela maquinaria escolar da Educação Infantil) dão ênfase para a produção de um sujeito infantil protagonista.

Interessante perceber que os referenciais italianos - não só eles, mas especialmente eles - relacionam a criança protagonista com au- 
tonomia, independência, competência, crescimento, desenvolvimento, aprendizagem. A criança protagonista é aquela que precisa investir no seu interesse, na sua liberdade de escolha, na sua autonomia, para empreender sua própria aprendizagem na escola infantil. Outra questão que chama a nossa atenção é que a centralidade na criança e a noção de interesse infantil permanecem até hoje, e talvez de forma mais pontual e intensa nos discursos pedagógicos atuais, sendo concebidas quase que de forma naturalizada pelos professores. Dito de outra forma, vemos emergir, discursivamente, a centralidade da criança no processo de aprendizagem e o interesse infantil para explicar muitas questões pedagógicas. As crianças protagonistas, referenciadas nas obras italianas, adquirem liberdade e autonomia para fazerem as suas próprias escolhas na instituição escolar desde tenra idade. Com Michel Foucault (2008), entendemos que a liberdade é a condição de existência para as relações de poder, sendo que as novas racionalidades de governamento estão permeadas pela liberdade de escolha de um cidadão livre, autônomo e empreendedor de si mesmo.

Em relação à prática docente, o que importa agora não é tanto rascunhar e observar para, depois, ao final de um processo mais longo registrar e interpretar. O que conta é mostrar, quase diariamente, os avanços, as aprendizagens, as conquistas, as novas aquisições das crianças na escola. Vale recorrer às ideias de Saraiva e Veiga-Neto (2009, p. 192), que nos mostram a passagem do capitalismo industrial para o capitalismo cognitivo e o deslocamento de ênfase da fábrica, "uma instituição de (re)produção de mercadorias”, para a empresa, "uma instituição de inovação", onde "o longo prazo já não parece fazer sentido. Vive-se no curto prazo, numa cultura do instantâneo" (Saraiva; Veiga-Neto, 2009, p. 193). O que importa agora "é a satisfação imediata dos desejos, que, tão logo satisfeitos se transformam em outros novos desejos a satisfazer" (Saraiva; Veiga-Neto, 2009, p. 193).

Ao documentarem-se as vivências das crianças na escola, há "o apelo para que cada criança se volte em direção àquilo que produziu, ao modo como se sentiu, aos sucessos ou dificuldades na execução de um projeto", e isso constitui uma estratégia para tornar cada criança “[...] consciente dos processos em que está envolvida, para dar-se conta dessa possibilidade de refletir sobre si mesma, de poder pensar o seu pensamento" (Bujes, 2008, p. 115-116). Essa prática opera no sujeito produzindo formas de ser e estar na escola, podendo ser compreendida como “[...] técnicas ou mecanismos de autovigilância, de auto-avaliação, de auto-narração (de confissão), que têm como efeitos a construção e a transformação da consciência de si” (Bujes, 2008, p. 116).

No caso da reconfiguração do papel do professor como um gerenciador de oportunidades, valorizando mais a organização do espaço escolar, acompanhamos nas práticas de registro da documentação pedagógica um certo afastamento da intervenção do professor em relação ao ensino. Ao celebrar a centralidade dos processos educacionais na criança, descentraliza-se, paulatinamente, as ações docentes. Essa descentralização não exclui o professor do processo educacional, pelo contrário; contudo faz movimentar outros modos de ser docente, esma- 
Registro Docente Contemporâneo

ecendo o ensino em detrimento da aprendizagem ${ }^{5}$. Os docentes minimizam suas ações em relação ao ensino e maximizam a liberdade individual para que cada criança seja capaz de aprender a aprender por si mesma, e isso fica claro na sugestão dada por Lóris Malaguzzi: "Jamais ensine a uma criança algo que ela possa aprender sozinha" (Malaguzzi apud Rinaldi, 2012, p. 229). Pretendemos marcar aqui uma nova posição de docência: um professor que distribui escolhas, através de um cardápio de oportunidades postas na organização do espaço escolar. Assim, o professor gerenciador de oportunidades apresenta-se como um tipo bastante particular de novos modos de ser docente na sociedade atual, e que está relacionada a circulação de novas discursividades e de um conjunto de verdades sobre os modos de viver a infância e a docência no nosso tempo presente.

\section{Para Continuar Pensando...}

As problematizações deste artigo têm caráter ainda exploratório, justamente por tratar-se de uma pesquisa de doutorado em Educação em andamento. Estamos atentas às práticas discursivas e não-discursivas em busca de ajuda; tal como apontam Miller e Rose (2012, p. 20), "para compreender as coisas, olhamos ao redor em busca de ajuda". Dito isso, podemos apontar para algumas conclusões provisórias deste trabalho, com o objetivo de continuar pensando sobre a infância contemporânea e os registros docentes voltados à abordagem da documentação pedagógica, bem como sobre os processos de subjetivação, tanto dos sujeitos infantis, quanto dos docentes da Educação Infantil.

Parece-nos que as práticas da Educação Infantil estão apontando, paulatinamente, para que as crianças sejam livres para escolher aquilo que querem fazer na escola. Os modos de praticar a vida na escola infantil mostram que as crianças precisam, elas próprias, empreender suas tarefas, sendo convocadas a ocupar o centro do processo pedagógico, uma vez que "as teorias e as metodologias que vêm orientando o trabalho pedagógico na atualidade, cada vez buscam mais a satisfação imediata. Isso pode ser percebido na importância hoje concedida ao interesse dos alunos" (Saraiva; Veiga-Neto, 2009, p. 198).

Em nossa opinião, há uma mudança de ênfase nas formas de registro docente sobre as aprendizagens da criança: do exame, das fichas, dos pareceres descritivos e relatórios trimestrais ou semestrais - que resguardavam um tempo analógico -, passamos a detalhar a biografia da criança na escola para além dos conteúdos, considerando também seu comportamento, gosto, afinidades, amizades. Mediante registros que contemplam fotografias, filmagens, portfólios, anedotários, produções das crianças, montagem de slides e transcrições de falas, entre outras formas de registro postuladas pela abordagem da documentação pedagógica de inspiração italiana, valorizamos um tempo digital e, portanto, bastante efêmero, pontilhista, fugaz e instantâneo.

Na medida em que acreditamos que a documentação pedagógica é uma possibilidade mais justa e sem julgamentos de avaliação por contemplar ferramentas tecnológicas de registro centradas naquilo que as

1116 Educação \& Realidade, Porto Alegre, v. 42, n. 3, p. 1103-1122, jul./set. 2017. 
crianças produzem na escola a partir de seus próprios interesses, estamos colocando em ação técnicas mais refinadas e alargadas de registro que capturam a minúcia de um detalhe. As práticas de registro docente sobre a aprendizagem infantil - seus deslocamentos e novos modos de fazer - estão articuladas com a infância contemporânea e com a racionalidade neoliberal, em que as mudanças sociais vão sendo "derretidas” para dar espaço à leveza dos líquidos, à instabilidade, à incerteza e à insegurança nas ações das pessoas (Bauman, 2001; 2007; 2009).

Nossa intenção foi mostrar como a documentação pode ser uma forma de registro docente sobre a aprendizagem escolar infantil que atende aos desafios da Contemporaneidade, mas que, como uma verdade naturalizada, precisa ser questionada. Partindo da premissa do filósofo francês Michel Foucault de que "nem tudo é ruim, mas tudo é perigoso, o que não significa exatamente o mesmo que ruim" (Foucault, 2010, p. 299), sentimos que pouco se discute sobre a produtividade de tais referenciais para algumas relações entre professor e aluno da Educação Infantil; por outro lado, é preciso ficar atento para o que se tem produzido nas práticas pedagógicas dos professores deste tempo digital, que assumem a documentação pedagógica como acima de qualquer suspeita e como uma proposta que pode servir para todos os alunos em qualquer situação. Se considerarmos que "tudo é perigoso, [e que] então temos sempre algo a fazer" (Foucault, 2010, p. 299), nossa intenção é levantar os questionamentos feitos neste escrito, os quais podem ajudar-nos a avançar no sentido de selecionar práticas pedagógicas que sempre sejam problematizadas em seus sentidos e relações de poder, pois acabam produzindo os sujeitos infantis e os docentes destes tempos digitais. Quando a sociedade (e com ela a escola) passa a produzir a exacerbação do individualismo e o destino parece apontar para uma única possiblidade, temos que optar por ensinar sob outras bases, para que nossas crianças possam ter outras possibilidades de viver o contemporâneo.

Recebido em 04 de dezembro de 2015 Aprovado em 07 de dezembro de 2016

\section{Notas}

1 Destacamos a palavra mais propositalmente, a fim de fazer uma analogia com o Programa Mais Educação, do Ministério da Educação do Brasil, ofertado às escolas públicas de Ensino Fundamental para oferecer atendimento de turno integral. Também na esfera do Governo Federal, o Programa Mais Médicos, com ações conjuntas entre os Ministérios da Saúde e da Educação, parece apontar para uma necessidade particular. "Mais" parece-nos uma palavra de ordem das atuais políticas públicas, nas diferentes esferas governamentais, e a Educação Infantil, enquanto primeira etapa da Educação Básica, não escapa disto: mais vagas para creche, mais obrigatoriedade de atendimento na pré-escola, mais jornada escolar em turno integral, entre outros aspectos.

2 A Roda dos expostos ou roda dos rejeitados era uma forma de excluir as crianças recém nascidas, as quais ficavam sob a guarda de instituições religiosas de caridade. No século XIX, com a influência das luzes e da medicina higienista, perdeu-se o cunho caritativo e passou-se a conceber a roda dos expostos como 
algo imoral, contra os interesses do Estado. Sobre este assunto, é possível buscar maior aprofundamento também no livro de Sandra Mara Corazza, intitulado "História da infância sem fim" (Corazza, 2000).

3 Destacamos também a crescente produção de dissertações e teses sobre a temática, como Mendonça (2009), Azevedo (2009), Marques (2010), Baracho (2011), Focchi (2013) e Vieira (2013), bem como a o aumento da publicação de artigos em periódicos, como Sá (2010), Gontijo (2011), Marques eAlmeida (2011a; 2011b, 2012) e Albarez e Gontijo (2012).

4 Reggio Emilia é uma cidade italiana da regiaõ de Emília Romanha, ao norte da Itália. Em 1991 Reggio Emilia recebeu o selo de As Dez melhores escolas do mundo pela revista Newsweek. Além desta cidade, outras propostas de Educação Infantil são reconhecidas mundialmente, tais como a cidade italiana de San Miniato, Parma, Firenze, Bolonha, Pistóia, entre outras.

5 Vale recorrer aos estudos de Biesta $(2013 ; 2016)$ e de Noguera-Ramírez (2011), que nos mostram a passagem de uma linguagem da educação ou de uma sociedade do ensino, para a linguagem da aprendizagem ou da sociedade de aprendizagem.

\section{Referências}

ALBAREZ, Nathalie; GONTIJO, Flávia. Diálogos entre a pós-modernidade e a prática de documentação pedagógica. Revista Paidéia, Belo Horizonte, Universidade FUMEC, ano 09, n. 12, p. 75-97, jan./jun, 2012.

AZEVEDO, Ana. Revelando as Aprendizagens das Crianças: a documentação pedagógica. 2009. 260 f. Dissertação (Mestrado em Estudos da Criança) - Programa de Pós-Graduação, Universidade do Minho, Portugal, 2009.

AZEVEDO, Ana; OLIVEIRA-FORMOSINHO, Júlia. A documentação da aprendizagem da criança: a voz das crianças. In: OLIVEIRA-FORMOSINHO, Júlia (Org.). A Escola Vista pelas Crianças. Porto: Porto Editora, 2008. P. 117 -143.

BARACHO, Nayara. A Documentação na Abordagem de Reggio Emilia para a Educação Infantil e suas Contribuições para as Práticas Pedagógicas: um olhar e as possibilidades em um contexto brasileiro. 2011. 234 f. Dissertação (Mestrado em Educação) - Faculdade de Educação da Universidade de São Paulo, São Paulo, 2011.

BAUMAN, Zygmunt. Modernidade Líquida. Rio de Janeiro: Zahar, 2001.

BAUMAN, Zygmunt. Vida Líquida. Rio de Janeiro: Zahar, 2007.

BAUMAN, Zygmunt. Tempos Líquidos. Rio de Janeiro: Zahar, 2009.

BECK, Ulrich. Modernização Reflexiva: política, tradição e estética na ordem social moderna. São Paulo: UNESP, 1997.

BIESTA, Gert. Devolver la enseñanza a la educación. Uma resposta a la desaparición del maestro. Revista Pedagogía y Saberes, Bogotá, Colômbia, Universidad Pedagógica Nacional, n. 44, p. 119-129, 2016.

BIESTA, Gert. Para Além da Aprendizagem: educação democrática para um futuro humano. Belo Horizonte: Autêntica Editora, 2013. (Coleção Educação: Experiência e Sentido).

BRASIL. Constituição Federal de 1988. Diário Oficial [da República Federativa do Brasil], Brasília/DF, 05 out. 1988. P. 1. Disponível em <http://www.planalto. gov.br/ ccivil_03/Constituicao/ConstituicaoCompilado.htm>. Acesso em: 14 set. 2014.

1118 Educação \& Realidade, Porto Alegre, v. 42, n. 3, p. 1103-1122, jul./set. 2017. 
BRASIL. Congresso Nacional. Lei no 8.069 de 13 de julho de 1990. Dispõe sobre o Estatuto da Criança e do Adolescente e dá outras providências. Diário Oficial da União, Brasília, Ministério da Justiça, 1990.

BRASIL. Lei no 9.394, de 20 de dezembro de 1996. Estabelece as Diretrizes e Bases da Educação Nacional. Diário Oficial [da República Federativa do Brasil], Brasília, DF, v. 134, n. 248, 23 dez. 1996. Seção 1. P. 27834-27841.

BRASIL. Ministério da Educação e do Desporto. Secretaria de Educação Fundamental. Referencial Curricular Nacional para a Educação Infantil. Brasília: MEC/SEC, 1998.

BRASIL. Ministério da Educação. Secretaria da Educação Básica. Diretrizes Curriculares Nacionais para a Educação Infantil. Brasília: MEC/SEC, 2010.

BRASIL. Ministério da Educação. Plano Nacional de Educação 2014-2024: Lei no 13.005 , de 25 de junho de 2014, que aprova o Plano Nacional de Educação (PNE) e dá outras providências. Brasília: Câmara dos Deputados, Edições Câmara, 2014. $86 \mathrm{p}$

BUCKINGHAM, David. Crescer na Era das Mídias Eletrônicas. São Paulo: Loyola, 2007.

BUJES, Maria Isabel Edelweiss. Artes de governar a infância: linguagem e naturalização da criança na abordagem de educação infantil da Reggio Emília. Educação em Revista, Belo Horizonte, Faculdade de Educação da Universidade Federal de Minas Gerais, n. 48, p. 101-123, 2008.

BUJES, Maria Isabel Edelweiss. Infância e Maquinarias. Rio de Janeiro: P\&A, 2002.

CEPPI, Giulio; ZINI, Michele (Org.). Crianças, Espaços, Relações: como projetar ambientes para a educação infantil. Porto Alegre: Penso, 2013.

CORAZZA, Sandra Mara. História da Infância sem Fim. Ijuí: UNIJUÍ, 2000.

DAHLBERG, Gunilla; MOSS, Peter; PENCE, Alan. Qualidade na Educação da Primeira Infância: perspectivas pós-modernas. Porto Alegre: Artmed, 2003.

EDWARDS, Carolyn; GANDINI, Lella; FORMAN, George. As Cem Linguagens da Criança: a abordagem de Reggio Emilia na Educação da primeira infância. Porto Alegre: Calábria, 1999.

EDWARDS, Carolyn; GANDINI, Lella; FORMAN, George (Org.). As Cem Linguagens da Criança: a experiência de Reggio Emilia em transformação. Porto Alegre: Penso, 2016.

FABRIS, Elí Henn; TRAVERSINI, Clarice. Conhecimentos escolares sob outras configurações: efeitos das movimentações disciplinares e de controle? In: TRAVERSINI, Clarice (Org.). Currículo e Inclusão na Escola de Ensino Fundamental. Porto Alegre: Edipucrs, 2013. P. 33-54.

FOCCHI, Paulo. "Mas os Bebês Fazem o quê no Berçário, Heim?”: documentando ações de comunicação, autonomia e saber-fazer de crianças de 6 a 14 meses em um contexto de vida coletiva. 2013. 172 f. Dissertação (Mestrado em Educação) - Programa de Pós-Graduação em Educação, Universidade Federal do Rio Grande do Sul, 2013.

FORTUNATI, Aldo. A Educação Infantil como Projeto da Comunidade. Porto Alegre: Artmed, 2009.

FORTUNATI, Aldo. A Abordagem de San Miniato para a Educação das Crianças: protagonismo das crianças, participação das famílias e responsabilidade da comunidade por um currículo do possível. Itália: Edizioni ETS, 2014.

Educação \& Realidade, Porto Alegre, v. 42, n. 3, p. 1103-1122, jul./set. 2017. 
FOUCAULT, Michel. Segurança, Território, População. São Paulo: Martins Fontes, 2008.

FOUCAULT, Michel. O sujeito e o poder. In: DREYFUS, Hubert; RABINOW, Paul. Michel Foucault: uma trajetória filosófica. Rio de Janeiro: Forense, 2010. P. 231-249.

FREINET, Celestin. Para uma Escola do Povo: guia prático para a organização material, técnica e pedagógica da escola popular. Lisboa: Presença, 1969.

FREINET, Celestin. As Técnicas Freinet na Escola Moderna. Lisboa: Estampa, 1976. FREIRE, Madalena. Observação, Registro, Reflexão: Instrumentos metodológicos I. São Paulo: Espaço Pedagógico, 1996.

GANDINI, Lella; HILL, Lynn; CADWELL, Louise; SCHWALL, Charles (Org.). 0 Papel do Ateliê na Educação Infantil: a inspiração de Reggio Emilia. Porto Alegre: Penso, 2012.

GANDINI, Lella; EDWARDS, Carolyn (Org.). Bambini: a abordagem italiana à educação infantil. Porto Alegre: Artmed, 2002.

GANDINI, Lella; GOLDHABER, Jeanne. Duas reflexões sobre a documentação. In: GANDINI, Lella; EDWARDS, Carolyn (Org.). Bambini: A abordagem italiana à Educação Infantil. Porto Alegre: Artmed, 2002. P. 150-169.

GIDDENS, Anthony. As Consequências da Modernidade. São Paulo: UNESP, 1991.

GONTIJO, Flávia. A documentação Pedagógica como instrumento de reflexão e produção docente na educação infantil. Paidéia, Belo Horizonte, Universidade FUMEC, n.10, p. 119-134, jan./jun. 2011.

KINNEY, Linda; WHARTON, Pat. Tornando Visível a Aprendizagem das Crianças. Porto Alegre: ARTMED, 2009.

KRAMER, Sonia. A Política do Pré-Escolar no Brasil: a arte do disfarce. São Paulo: Editora Cortez, 2001.

KUHLMANN JUNIOR, Moysés. Infância e Educação Infantil: uma abordagem histórica. Porto Alegre: Mediação, 1998.

LIPOVETSKY, Gilles. A Era do Vazio: ensaio sobre o individualismo contemporâneo. Lisboa: Relógio d’Água, 1989.

LOCKMANN, Kamila; MOTA, Maria Renata Alonso. Práticas de assistência à infância no Brasil: uma abordagem histórica. Revista Linhas, Florianópolis, Universidade do Estado de Santa Catarina, v. 14, n. 26, p. 76-111, jan./jun. 2013.

LUFF, Paulette. Observações escritas ou caminhadas pelo parque? Documentando as experiências das crianças. In: MOYLES, Janete (Org.). Fundamentos da Educação Infantil: enfrentando o desafio. Porto Alegre: Artmed, 2010. P. 205-216. LYOTARD, Jean-François. A Condição Pós-Moderna. Rio de Janeiro: José Olympio, 1998.

MALAGUZZI, Lóris. História, Ideias e Filosofia Básica. In: EDWARDS, Carolyn; GANDINI, Lella; FORMAN, George. As Cem Linguagens da Criança: a abordagem de Reggio Emilia na Educação da primeira infância. Porto Alegre: Calábria, 1999. P. 59-104.

MARCÍLIO, Maria Luiza. A roda dos expostos e a criança abandonada na história do Brasil: 1726-1950. In: FREITAS, Marcos Cezar (Org.). História Social da Infância no Brasil. São Paulo: Cortez, 2003. P. 53-80.

MARÍN-DÍAZ, Dora. Morte da infância moderna ou construção da quimera infantil? Educação \& Realidade, Porto Alegre, Faculdade de Educação da Universidade Federal do Rio Grande do Sul, v. 35, n. 3, p. 193-211, set./dez. 2010.

1120 Educação \& Realidade, Porto Alegre, v. 42, n. 3, p. 1103-1122, jul./set. 2017. 
MARQUES, Amanda Cristina Teagno Lopes; ALMEIDA, Maria Isabel de. Registro de práticas e formação de professores: reflexão, memória e autoria. Educação: teoria e prática, São Paulo, Universidade Estadual Paulista Júlio de Mesquita Filho, v. 21, n. 37, p. 169-188, set./dez. 2011a.

MARQUES, Amanda Cristina Teagno Lopes; ALMEIDA, Maria Isabel de. A documentação pedagógica na Educação Infantil: traçando caminhos, construindo possibilidades. Educação Pública, Cuiabá, Universidade Federal de Mato Grosso, v. 20, n. 44, p. 413-428, set./dez. 2011b.

MARQUES, Amanda Cristina Teagno Lopes; ALMEIDA, Maria Isabel de. A documentação pedagógica na abordagem italiana: apontamentos a partir de pesquisa bibliográfica. Diálogo Educacional, Curitiba, Pontifícia Universidade Católica do Paraná, v. 12, n. 36, p. 447-464, maio/ago. 2012.

MENDONÇA, Cristina Nogueira. A Documentação Pedagógica como Processo de Investigação e Reflexão na Educação Infantil. 2009. 137 f. Tese (Doutorado em Educação) - Programa de Pós-Graduação em Educação, Faculdade de Filosofia e Ciências da Universidade Estadual Paulista Júlio de Mesquita Filho, Marília, 2009.

MILLER, Peter; ROSE, Nikolas. Governando o Presente. São Paulo: Paulus, 2012. MONTESSORI, Maria. Pedagogia Científica. São Paulo: Flamboyant, 1965.

NARODOWSKI, Mariano. Adeus à infância (e à escola que a educava). In: SILVA, Luiz Heron da (Org.). A Escola Cidadã no Contexto da Globalização. Petrópolis: Vozes, 1998, P. 172-177.

NOGUERA-RAMÍREZ, Carlos Ernesto. Pedagogia e Governamentalidade: ou da modernidade educativa para uma sociedade educativa. Belo Horizonte: Autêntica, 2011.

Ó, Jorge Ramos do. A criança problema e o seu governo em Portugal e no Brasil (1880-1960): discursos e práticas. In: Ó, Jorge Ramos do; CARVALHO, Luís Miguel. Emergência e Circulação do Conhecimento Psicopedagógico Moderno (1880-1960): estudos comparados Portugal-Brasil. Lisboa: EDUCA, 2009. P. $15-147$.

OLIVEIRA, Zilma de Moras. Creches no sistema de ensino. In: MACHADO, Maria Lúcia (Org.). Encontros e Desencontros em Educação Infantil. São Paulo: Cortez, 2002. P. 79-82.

POPKEWITZ, Thomas S. História do Currículo, Regulação Social e Poder. In: SILVA, Tomaz Tadeu da (Org.). O Sujeito da Educação: estudos foucaultianos. Rio de Janeiro: Editora Vozes, 1994. P. 173-210.

POPKEWITZ, Thomas; OLSSON, Ulf; PETERSSON, Kenneth. Sociedade da Aprendizagem, Cosmopolitismo, Saúde Pública e Prevenção à Criminalidade. Educação \& Realidade, Porto Alegre, Faculdade de Educação da Universidade Federal do Rio Grande do Sul, v. 34, n. 2, p. 73-96, maio/ago. 2009.

POSTMAN, Neil. O Desaparecimento da Infância. Rio de Janeiro: Graphia, 1999. RABITTI, Giordana. À Procura da Dimensão Perdida: uma Escola de Infância de Reggio Emilia. Porto Alegre: Artes Médicas, 1999.

RINALDI, Carla. Diálogos com Reggio Emilia: escutar, investigar, aprender. São Paulo: Paz e Terra, 2012.

SÁ, Alessandra. Um olhar sobre a abordagem educacional de Reggio Emilia. Paidéia, Belo Horizonte, Universidade FUMEC, ano 7, n. 8, p. 55-80, jan./jun. 2010.

Educação \& Realidade, Porto Alegre, v. 42, n. 3, p. 1103-1122, jul./set. 2017. 
SARAIVA, Karla; VEIGA-NETO, Alfredo. Modernidade Líquida, Capitalismo Cognitivo e Educação Contemporânea. Educação \& Realidade, Porto Alegre, Faculdade de Educação da Universidade Federal do Rio Grande do Sul, v. 34, n. 2, p. 87-201, maio/ago. 2009.

SARMENTO, Manuel Jacinto. As culturas da infância nas encruzilhadas da Segunda Modernidade. In: SARMENTO, Manuel Jacinto; CERISARA, Ana Beatriz. Crianças e Miúdos: perspectivas sociopedagógicas da infância e educação. Porto, Portugal: Asa Editores, 2004. P. 09-35.

SCHWALL, Charles. O ambiente e os materiais do ateliê. In: GANDINI, Lella (Org.). O Papel do Ateliê na Educação Infantil: a inspiração de Reggio Emilia. Porto Alegre: Penso, 2012. P. 31-47.

VEIGA-NETO, Alfredo. Delírios avaliatórios: o currículo desvia para a direita ou um farol para o currículo. In: FAVACHO, André Márcio; PACHECO, José Augusto; SALES, Shirlei Rezende. Currículo: conhecimento e avaliação - divergências e tensões. Curitiba: CRV, 2013. P. 155-175.

VIEIRA, Flaviana. A Formação de Professoras em uma Creche Universitária: o papel da documentação no processo formativo. 2013. 245 f. Dissertação (Mestrado em Educação) - Programa de Pós-Graduação em Educação, Universidade de São Paulo, São Paulo, 2013.

WARSCHAUER, Cecília. A Roda e o Registro: uma parceria entre o professor, alunos e conhecimento. Rio de Janeiro: Paz e Terra, 1993.

Cláudia Inês Horn é professora do Centro de Ciências Humanas e Sociais do Centro Universitário Univates. Coordenadora do Laboratório Brinquedoteca e dos Estágios do Curso de Pedagogia Univates. Cursou Pedagogia pela Univates e Mestrado em Educação pela Universidade Federal do Rio Grande do Sul (UFRGS). Atualmente é Doutoranda em Educação pela Universidade do Vale do Rio dos Sinos (Unisinos). Membro do Grupo Interinstitucional de Pesquisa em Pedagogias, Docências e Diferenças (GIPEDI/ CNPq).

E-mail: cihorn@univates.br

Elí Henn Fabris é professora e pesquisadora do PPG em Educação da Universidade do Vale do Rio dos Sinos (Unisinos). Cursou Pedagogia pela Universidade de Passo Fundo (UPF), mestrado e doutorado em Educação pela Universidade Federal do Rio Grande do Sul (UFRGS) e Pós-doutorado na UPorto/Portugal. É coordenadora do Programa de Pós-Graduação em Educação da Unisinos e do Grupo Interinstitucional de Pesquisa em Pedagogias, Docências e Diferenças (GIPEDI, CNPq). Bolsista de Produtividade em Pesquisa do CNPq - Nível 2 - CA ED - Educação.

E-mail: efabris@unisinos.br 